\title{
Thermal and hydrothermal stability of hierarchical porous silica materials
}

\author{
Jean-Luc Blin $^{1 *}$, Philippe Riachy ${ }^{1}$, Cédric Carteret $^{2}$ and Bénédicte Lebeau ${ }^{3}$
}

Prof. Jean-Luc Blin (Jean-Luc.Blin@univ-lorraine.fr) and Dr. Philippe Riachy (philip.riachy@gmail.com)

${ }^{1}$ Université de Lorraine/CNRS, L2CM, UMR7053, F-54506 Vandoeuvre-lès-Nancy cedex, France

Prof. Cédric Carteret (cedric.carteret@univ-lorraine.fr)

${ }^{2}$ : Université de Lorraine/CNRS, LCPME, UMR7564, F-54600 Villers-lès-Nancy, France

Dr. Bénédicte Lebeau (benedicte.lebeau@uha.fr)

3: Université de Haute Alsace (UHA)/CNRS, IS2M, UMR 7361, 68093 Mulhouse cedex, France.

* Corresponding authors:

Prof. Jean-Luc Blin

Université de Lorraine

UMR CNRS 7053 L2CM

Faculté des Sciences et Technologies

BP 70239

F-54506 Vandoeuvre-lès-Nancy cedex, France

Tel. +33 383684370

E-mail: Jean-Luc.Blin@univ-lorraine.fr

http://www.12cm.univ-lorraine.fr/12cm/ 


\begin{abstract}
In this study, we have investigated the thermal and hydrothermal stability of a dual mesostructured silica and of a macro-mesoporous silica.

Concerning the thermal stability, results obtained by SAXS, nitrogen adsorption-desorption analysis and infrared spectroscopy show that, the macro-mesoporous material is stable up to $550{ }^{\circ} \mathrm{C}$, the mesostructure being only slightly damaged, but a contraction of both the macropores and the mesopores is observed upon calcination. Considering the dual mesoporous silica, regardless the calcination temperature, the matrix with small pores is completely degraded whereas the one with the larger pores is only weakly damaged.

With regard to hydrothermal stability, all the investigated hierarchical porous silica are damaged when they are plunged into boiling water because of the hydrolysis of the superficial $\mathrm{Si}-\mathrm{O}-\mathrm{Si}$ linkages, involved by water molecules adsorbed on the silanol groups. The extracted and calcined macro-mesoporous material is stable for one hour in boiling water, whereas the non-calcined sample is stable for only 30 minutes. The collapse reaches only the mesopores, the macropores remain unaltered. The dual mesostructured silica is also sensitive to boiling water, but two kinetics of degradation, which correspond to each matrix, are observed. The network having small pores disintegrates after 3 hours, while the matrix having large pores begins to collapse after 8 hours. This behavior has been attributed to the difference in the mesopore wall thickness between both matrixes.
\end{abstract}

Keywords: Dual mesoporosity, Macro-mesoporosity, Silica, Hydrothermal stability, Thermal stability 


\section{Introduction}

Due to their properties such as a high specific surface area and a uniform pore diameter, the porous silica are of particular interest in various domains, such as adsorbents, catalysts, host matrices for electronic and photonic devices, drug delivery systems and sensors ${ }^{[1-5]}$. For example, they can be used as support for enzyme immobilization to prepare supported biocatalysts $^{[6-9]}$. Some of these applications impose critical conditions on those materials, for instance in catalysis the regeneration of catalysts is often realized at high temperatures under steam. The thermal and hydrothermal stability are thus important parameters to take into account in order to design the right material for a given application. Silica materials are made from interlinked $\mathrm{SiO}_{4}$ tetrahedra and at the surface, the structure terminates in either a siloxane group $(\equiv \mathrm{Si}-\mathrm{O}-\mathrm{Si} \equiv)$ with the oxygen on the surface, or one of several forms of silanol groups ( $\equiv \mathrm{Si}-\mathrm{OH})$. Several types of surface silanols such as isolated groups (or free silanols), where the surface silicon atom has three bonds into the bulk structure and the fourth bond attached to a single -OH group, and vicinal silanols (or bridged silanols), where two single silanols groups, attached to different silicon atoms, are close enough to hydrogen bond. A third type of silanols, the germinal ones, consists of two hydroxyl groups that are attached to one silicon atom ${ }^{[10]}$. In the presence of water or even of moisture, due to the silicate hydrolysis by water adsorbed on the silanol groups, a structure collapse is possible. A breakdown of their structure is also observed when the samples are stored for a few months under ambient conditions or wetted at room temperature in water and then recalcinated ${ }^{[11,12]}$. For example, it is reported in literature that materials like the M41S family have a poor hydrothermal stability in boiling water and steam due to silicate hydrolysis ${ }^{[13,14]}$. The thermal stability was found to be strongly related to the wall thickness and the silica precursor ${ }^{[15]}$, and the hydrothermal stability is influenced by three factors. First of all, it was shown that materials with very polymerized or condensed silica are less affected in boiling water 
conditions. Secondly, the thicker the pore wall is, the more stable the material is. The third factor is the pore structure and affinity ; it has been shown that the cubic MCM-48 has a lower structural degradation than that of the hexagonal mesoporous materials MCM-41 ${ }^{[16]}$. Since the presence of the strained siloxane bonds, which are easily hydrolyzed in the presence of water or even of moisture ${ }^{[17]}$, is mainly responsible for the low hydrothermal stability of silica materials, some attempts to stabilize the structure of mesoporous materials have been reported in the literature. For instance, post-synthesis treatments like coating the pore interiors by a hydrophilic layer ${ }^{[18]}$, grafting and ion exchange ${ }^{[17,19]}$ and post-synthesis treatment in water in the presence a surfactant afford more stable silica frameworks ${ }^{[20]}$. The key idea is, however, the preparation of materials with more silica condensation in the pore walls in order to enhance the hydrothermal stability and to have the less possible terminal hydroxyl groups that make the structure unstable under hydrothermal and steam conditions ${ }^{[1,15]}$. One way to prepare the porous silica materials consists in combining the sol-gel process and the surfactant templating mechanism. Depending on the building blocks, i.e. micelles, microemulsions, liquid crystals or emulsions, different kinds of porous materials can be prepared. Recently, we have reported the synthesis of dual mesostructured silica templated by a mixture of hydrogenated (Pluronic P123) and fluorinated micelles $\left[\mathrm{R}_{8}^{\mathrm{F}}(\mathrm{EO})_{9}\right]$ via a self-assembly mechanism. This material presents two mesopore sizes distribution, one centered around at $9.5 \mathrm{~nm}$ and the second around $3.5 \mathrm{~nm}^{[21]}$. We have also taken advantage of the homogeneity in size of nano-emulsions to design hierarchical macro-mesoporous silica offering porosity both in the mesopore range (about $9 \mathrm{~nm}$ ) and in the macropore range (around $230 \mathrm{~nm}$ ) by combining the nano-emulsions templating mechanism with the cooperative templating one ${ }^{[22]}$. The hierarchical porous materials have been synthesized in the presence of both the nanoemulsion and of the P123 micelles. If the thermal and hydrothermal stability of the mesoporous silica was investigated in literature ${ }^{[14,16,23-25]}$, the one of hierarchical porous 
materials is barely reported ${ }^{[26]}$. In this respect, here we have investigated both the thermal and the hydrothermal stability of the two types of hierarchical porous silica, recently reported.

\section{Results and discussion}

\subsection{Thermal stability}

Dual mesoporous silica: The SAXS patterns show the presence of 3 peaks for the un-calcined dual-mesoporous material. As reported previously, the first $(11.2 \mathrm{~nm})$ and second $(6.2 \mathrm{~nm})$ peaks correspond to the (100) and (110) reflections, respectively of the hexagonal structure of the matrix that is templated by the P123-riched micelles and the third peak corresponds to the (100) reflection of the hexagonal structure of the matrix templated by the fluorinated-rich micelles ${ }^{[21,27]}$. It should be noted that this peak and the (200) reflection of the network induced by the P123-riched micelles overlaps. The unit cell $\left(\mathrm{a}_{0}=2 \mathrm{~d}_{100} / \sqrt{3}\right)$ which corresponds to the sum of the pore diameter and the thickness of the pore wall, is equal to 12.9 and $6.0 \mathrm{~nm}$ for the large and small mesopores network, respectively. After calcination, the reflections characteristic of the smaller mesopore arrangement progressively disappear, meaning that the small mesopore network is damaged by the calcination process, whereas the larger one is not significantly affected. For the latter we just note a network contraction since the d-spacing values vary from 11.2 to $10.1 \mathrm{~nm}$ after calcination at $450^{\circ} \mathrm{C}$ (Fig. 1A). This phenomenon can be attributed to a condensation of the $\mathrm{Si}-\mathrm{OH}$ groups. The progressive collapse of the small mesopores with the temperature is also supported by the nitrogen adsorption-desorption analysis. Indeed, while two inflection points at relative pressure $\mathrm{p} / \mathrm{p}_{0}=0.4$ and $\mathrm{p} / \mathrm{p}_{0}=0.7$ are detected on the adsorption branch of the isotherm of the extracted material, after calcination the inflection point at $\mathrm{p} / \mathrm{p}_{0}=0.45$ gradually disappears (Fig. 1B). Since the pore diameter is related to the relative pressure via the Kelvin's equation, this reflects the collapse of the smallest network. 

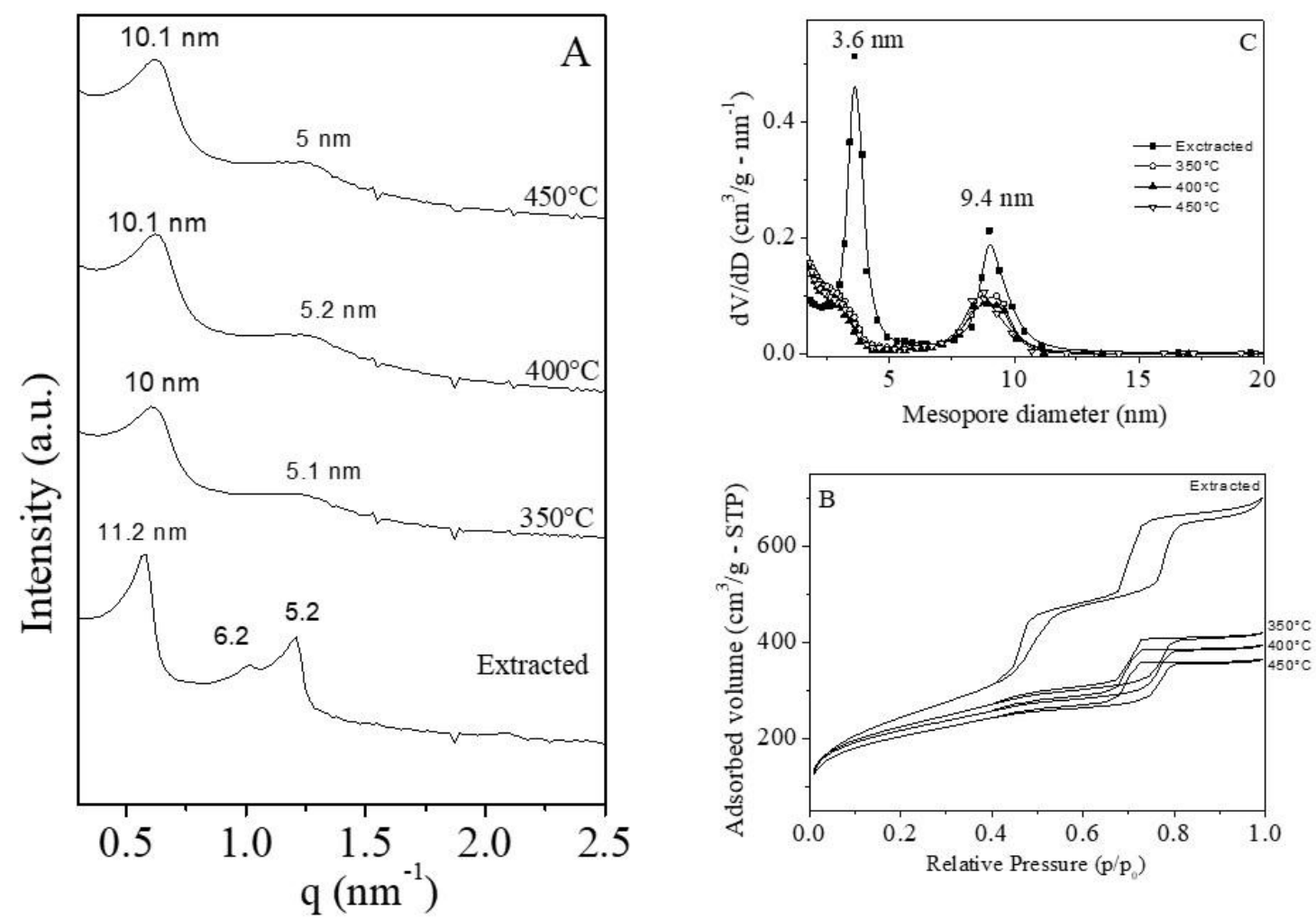

Figure 1: Dual mesoporous silica: SAXS patterns (A), nitrogen adsorption-desorption isotherms (B) and mesopore size distributions (C) of the extracted or extracted and calcined at various temperatures.

This trend is further confirmed by the mesopore size distributions depicted in Figure 1C. Two maxima at around 3.6 and $9.4 \mathrm{~nm}$ are clearly observed for the extracted material but after extraction and calcination the component around $9.4 \mathrm{~nm}$ remains, but its $\mathrm{dV} / \mathrm{dD}$ value decreases by half. The specific surface area is not strongly affected by the calcination process; we note a decrease of about $15 \%$ after calcination at $450^{\circ} \mathrm{C}$ (Table 1). By contrast, the effect is more pronounced for the pore volume. As a matter of fact, whatever the temperature, it decreases by $50 \%$ after the thermal treatment (Table 1). This shows that the thermal treatment of the dual-mesoporous silica material has a damaging effect. The matrix with the smaller pore size collapses when the temperature is applied while the matrix with the larger pore size is slightly damaged. This difference of behavior can be relied to the pore wall thickness of 
each network. The mesopore wall thickness is deduced by subtracting the pore size determined by the BJH method from the dimension of the unit cell; its value is found around 3.5 and $2.4 \mathrm{~nm}$ for the channel array templating by the pluronic-rich and the fluorinated-rich micelles, respectively. Thicker pore walls result in higher the thermal stability ${ }^{[16,28]}$. Therefore, the thinner pore walls of the matrix with the small pore size renders it prone to collapse under high temperatures and explains its faster decay compared with the matrix with the bigger pore size.

Table 1: Specific surface area and pore volume of the dual mesoporous material as a function of the calcination temperature

\begin{tabular}{ccc}
\hline Materials & $\begin{array}{c}\text { Specific surface area } \\
\left(\mathrm{m}^{2} / \mathrm{g}\right)\end{array}$ & Pore volume $\left(\mathrm{cm}^{3} / \mathrm{g}\right)$ \\
\hline Extracted & 880 & 1.00 \\
Extracted and calcined at $350^{\circ} \mathrm{C}$ & 780 & 0.50 \\
Extracted and calcined at $400^{\circ} \mathrm{C}$ & 760 & 0.48 \\
Extracted and calcined at $450^{\circ} \mathrm{C}$ & 750 & 0.45 \\
\hline
\end{tabular}

Macro-mesoporous silica: The SAXS pattern of the extracted material exhibits three peaks at 11.0, 6.3, and $5.5 \mathrm{~nm}$ (Fig. 2A). The relative positions of the Bragg reflections are: 1, $\sqrt{3}, 2$. As a consequence, they can be attributed to the (100), (110) and (200) reflections of the 2Dhexagonal structure of the mesopore network. The hexagonal cell parameter is found equal to $12.7 \mathrm{~nm}$. After calcination at $550^{\circ} \mathrm{C}$, the intensities of the reflection lines become weaker but the hexagonal arrangement is still observed. The calcination also caused a decrease of the hexagonal cell parameter from 12.7 to $11.0 \mathrm{~nm}$, this is linked to the shrinkage of the mesopores. The macropore size distribution of the extracted silica, determined by mercury intrusion porosimetry measurements, shows the presence of two macropore size distributions centered at $250 \mathrm{~nm}$ and $20 \mu \mathrm{m}$ (Fig. 2B). The first one arises from the mineralization of the nano-emulsions and the second one corresponds to interparticular porosity. After calcination 
the macropore size decreases to $150 \mathrm{~nm}$. This indicates that the thermal treatment of the meso-macroporous silica material causes the shrinkage of both the mesopores and macropores. It also involves a slight damage of the mesostructure, reflected by the loss in intensity of the reflections lines.
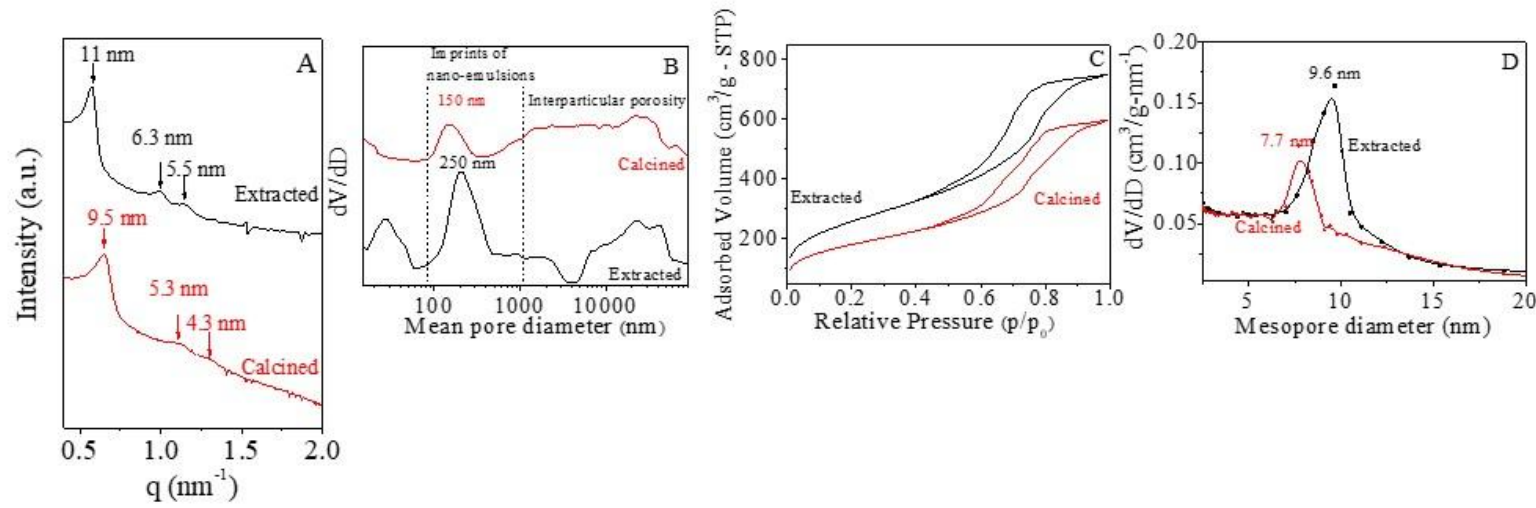

Figure 2: SAXS pattern (A), mercury intrusion porosimetry (B), nitrogen adsorptiondesorption isotherm (C) and mesopore size distribution (D) of the macromesoporous silica, which was extracted or extracted followed by calcination.

Both extracted and calcined silica show a type IV isotherm (Fig. 2C), characteristic of mesoporous materials according to the IUPAC classification ${ }^{[29]}$. Upon calcination the surface area and the pore volume decrease from 780 to $630 \mathrm{~m}^{2} / \mathrm{g}$ and from 1.2 to $0.8 \mathrm{~cm}^{3} / \mathrm{g}$, respectively, reflecting the slight damage of the mesostructure. The latter can arise from the elimination of the remaining surfactant in the mesopores after extraction. Indeed, the ethanol extraction can leave up to around $10 \%$ of the surfactant in the silica matrix ${ }^{[30,31]}$. Reducing the methylene oxide blocks in the silica walls creates void spaces in the walls, thus promoting the structural collapse ${ }^{[32]}$. After calcination, in accordance with the mesopore shrinkage, we note a shift of the pore size distribution maximum from 9.6 to $7.7 \mathrm{~nm}$ (Fig. 2D). In the meantime, because of the partial damage of the mesopore network, a decrease of the $\mathrm{dV} / \mathrm{dD}$ values is 
also noted. Furthermore, the pore wall thickness equal to $3.1 \mathrm{~nm}$ remains unchanged after the calcination.

From the results reported above, it appears that the calcination of the macro-mesoporous silica material causes the shrinkage of the meso and the macropores, this phenomenon is usually due to an enhancement of the cross-linking ${ }^{[33]}$, leading to less silanol groups at the surface.

\subsection{Hydrothermal stability}

Dual mesoporous silica: the hydrothermal stability assessment for the dual-mesoporous silica material was realized after ethanol extraction and drying only, since the thermal treatment leads to the collapse of the matrix with the small pore size. The SAXS patterns in Figure 3A, shows that the matrix with the smallest pore size collapses after 5 hours, while the one with the large pore size remains stable even after 24 hours in boiling water, although the intensity of the reflections decreases with time. Indeed, the (100), (110) and (200) reflections at 10.8, 6.1 and $5.3 \mathrm{~nm}$, which are attributed to the network templated by the Pluronic-rich micelles are still observed after this immersion time in boiling water (Fig. 3A). By contrast, the peak at $5.0 \mathrm{~nm}$ characteristic of the smallest mesopores is no longer detected after 5 hours in boiling water (Fig. 3A). The loss of the dual porosity when the stay in boiling water is prolonged is further confirmed by the evolution of the adsorption isotherms. The two inflection points at around $\mathrm{p} / \mathrm{p}_{0}=0.45$ and 0.75 are clearly observed until 5 hours in boiling water (Fig. 3B) but the $\mathrm{dV} / \mathrm{dD}$ values of the component at $3.6 \mathrm{~nm}$ decrease after 1 hour. Beyond this period, only one inflection point $\left(\mathrm{p} / \mathrm{p}_{0} \approx 0.75\right)$ is detected during the adsorption and the desorption steps. The small mesopores network is thus progressively destroyed when the treatment in boiling water is prolonged. Beyond 8 hours of immersion, the value of the relative pressure at which the capillary condensation occurs $\left(\mathrm{p} / \mathrm{p}_{0} \approx 0.75\right)$ is spread out over a larger range of relative pressure and the saturation is reduced. Since the $\mathrm{p} / \mathrm{p}_{0}$ position of the inflection point is related 
to the pore diameter according to Kelvin's equation, this observation suggests that an enlargement of the openings occurs with time. This is confirmed by the pore size distribution, which is very broad. The $\mathrm{dV} / \mathrm{dD}$ values also strongly decrease (Fig. $3 \mathrm{C}$ ), suggesting that the large mesopores become less homogeneous. Therefore, the second mesostructure slowly collapses, leading to amorphous silica with heterogeneous pore size. A breakdown of the wall separating two adjacent pores can occur and channels with larger inner pore diameter are formed $^{[12]}$.
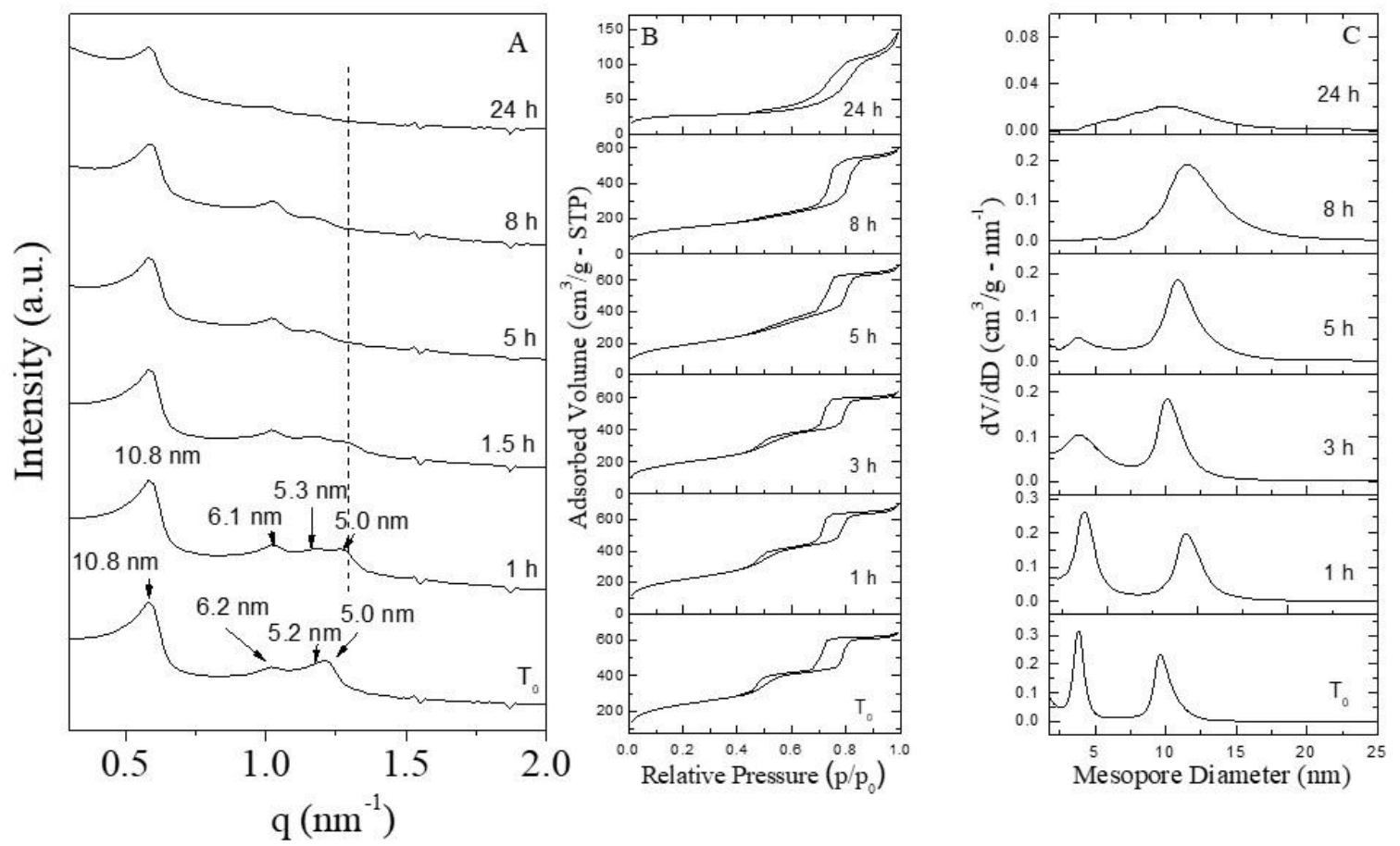

Figure 3 : Dual mesoporous materials : Evolution of the SAXS pattern (A), the nitrogen adsorption-desorption isotherms (B) with the corresponding mesopore size distribution $(\mathrm{C})$ as a function of the immersion time in boiling water.

The values of the specific surface area and of the pore volume sharply decrease between 0 and 3 hours of immersion (Fig. 4). E.g. for this period, their values drop from 879 to $690 \mathrm{~m}^{2} / \mathrm{g}$ $(21.5 \%)$ and from 0.94 to $0.82(13 \%)$, respectively. During the first hour, the decrease is about 8.5 and $5 \%$ for the specific surface area and the pore volume, respectively. After 8 
hours, the drop is more pronounced (45 and 29\%) and after 24 hours in boiling water, the surface area lost $90 \%$ of its initial value while the pore volume lost $80 \%$ (Fig. 4). This reflects an important surface alteration when the treatment in boiling water is prolonged.

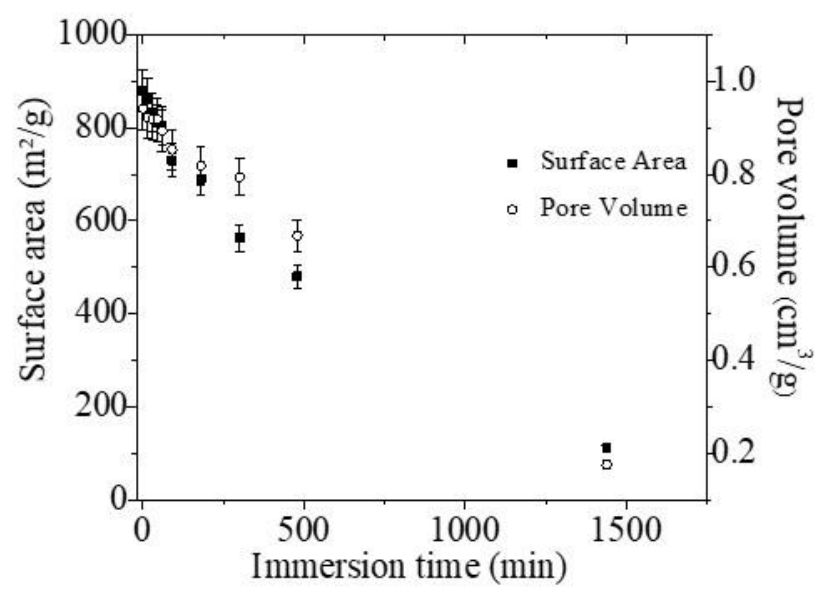

Figure 4: Dual mesoporous materials: evolution of the surface area and pore volume as a function of the immersion time

Macro-mesoporous silica: After 30 minutes in boiling water, the un-calcined material (Fig. 5A) lost its mesostructure while the collapse occurs after 60 minutes for the calcined sample (Fig. 5B). Indeed, until these durations, the secondary reflections are still distinguished. If the immersion time is increased, no secondary reflections are detected any longer on the SAXS pattern, meaning that the regular channel array is lost and that the collapse of the structure has begun. Nevertheless, the presence of the main diffraction peak at 10.8 (extracted) and $9.6 \mathrm{~nm}$ (extracted and calcined) indicates the persistence of the framework, but any order of the material extended over a long range. However, the intensity of the SAXS peak becomes much less intense, suggesting that the structure is partially destroyed. Initially, the nitrogen adsorption-desorption isotherms of both materials showed a sharp capillary condensation, this sharpness decayed and disappeared after 30 and 60 minutes for the extracted (Fig. 6A) and for the extracted and calcined (Fig. 6C) material, respectively. 

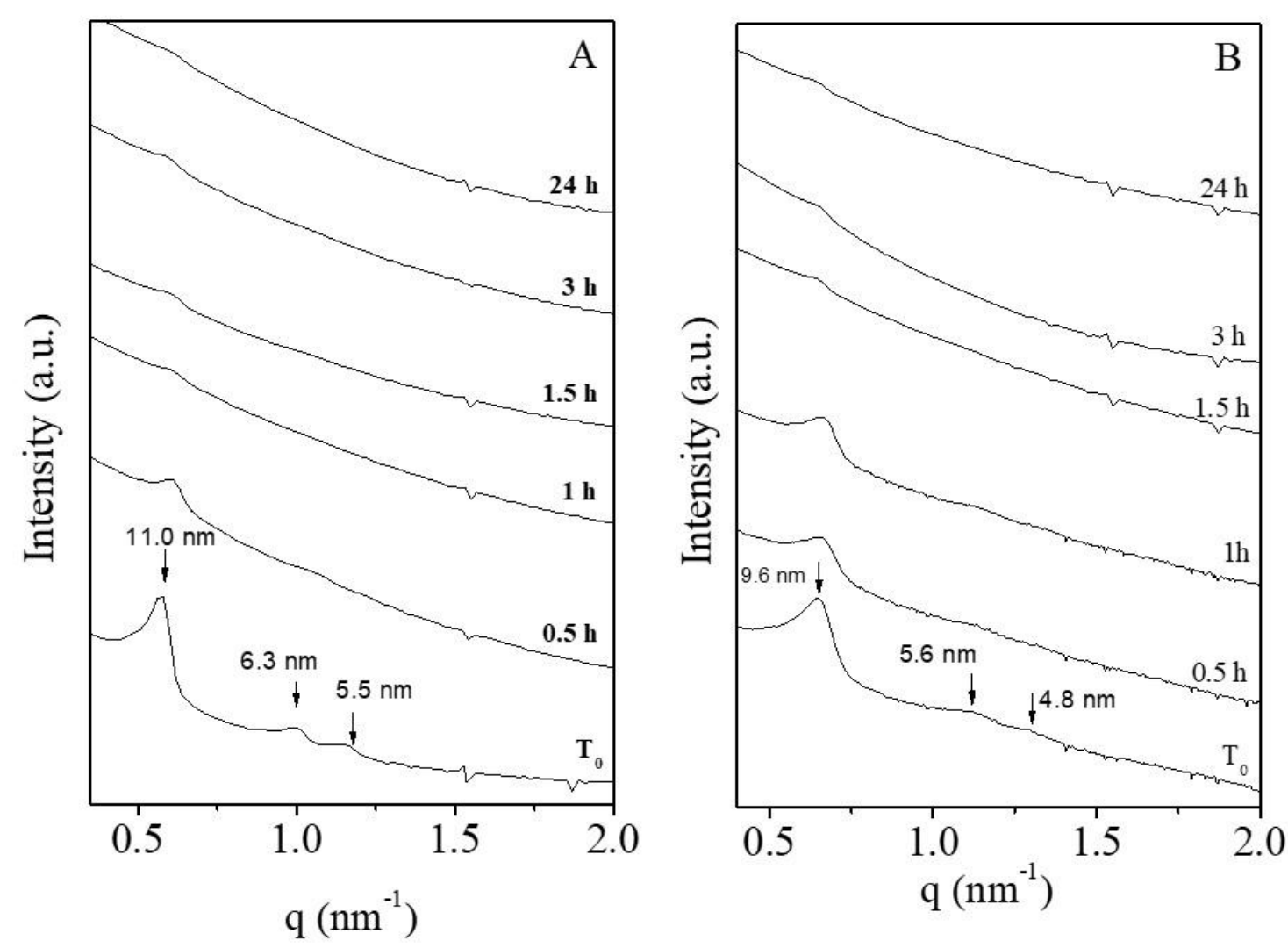

Figure 5: Evolution of the SAXS pattern with the immersion time into boiling water. The macro-mesoporous material has been extracted (A) or extracted and calcined (B).

The pore size distribution showed a gradual decrease in the $\mathrm{dV} / \mathrm{dD}$ value and the maximum disappeared after 30 minutes for the un-calcined material (Fig. 6B), and after 60 minutes for the calcined one (Fig. 6D). After a longer treatment in boiling water, the channels are progressively destroyed and the mesostructure slowly collapses, no maximum is detected in the mesopore size distribution anymore. These results are in good agreement with the SAXS analysis. Furthermore, the surface area and pore volume of the un-calcined material showed a fast decrease in the first 90 minutes, then a slower decrease (Fig. 7A). After 24 hours they sustained a loss of $40 \%$. On the other hand, the surface area and the pore volume of the extracted and calcined material showed a relatively slower decrease (Fig. 7B), and after 24 hours, the surface area lost $65 \%$ of its initial value and the pore volume $30 \%$. 

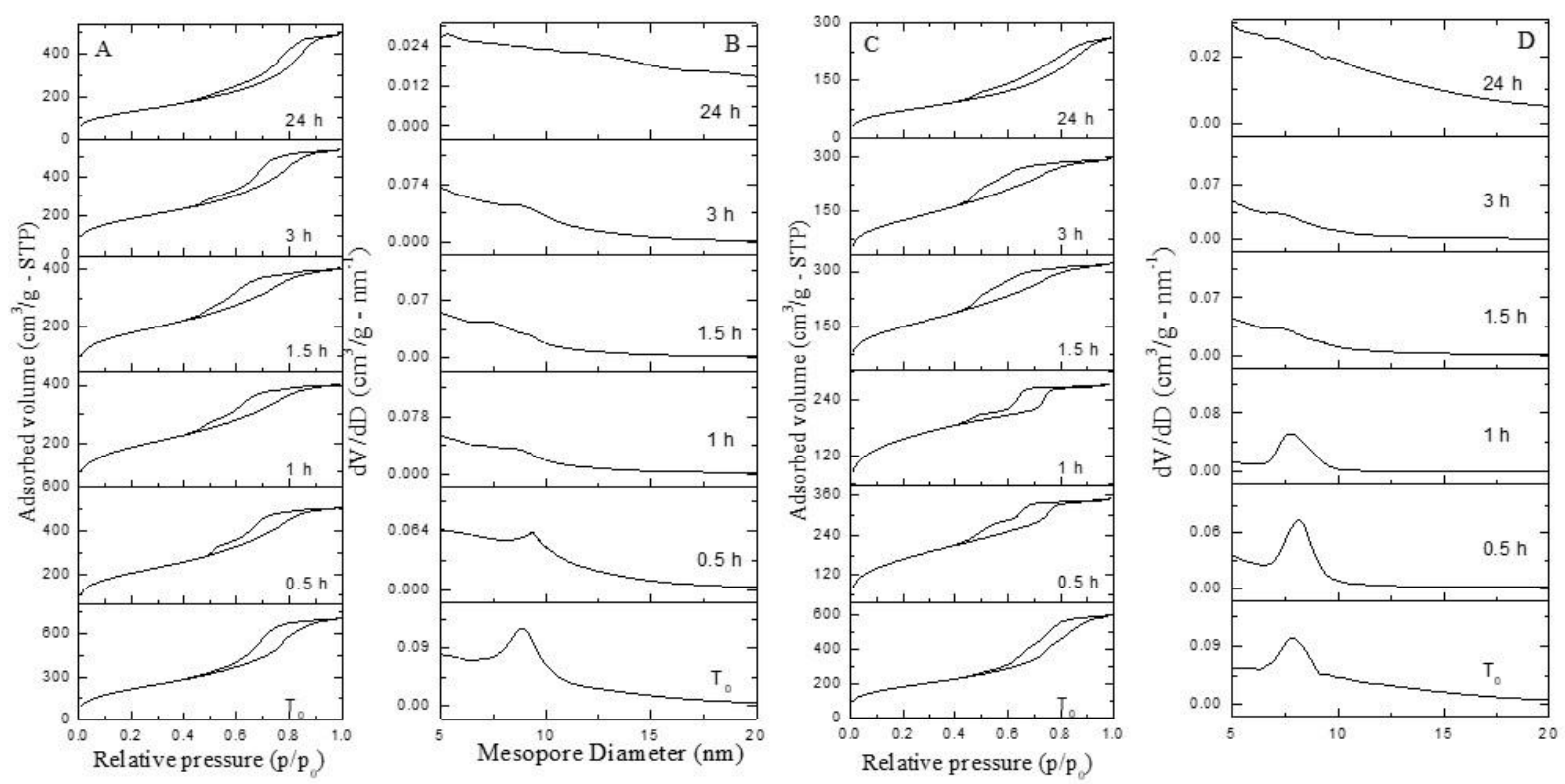

Figure 6: Evolution of the nitrogen adsorption-desorption isotherms with the corresponding mesopore size distribution of the extracted (A, C) and of the extracted followed by calcination $(\mathrm{B}, \mathrm{D})$ macro-mesoporous materials.
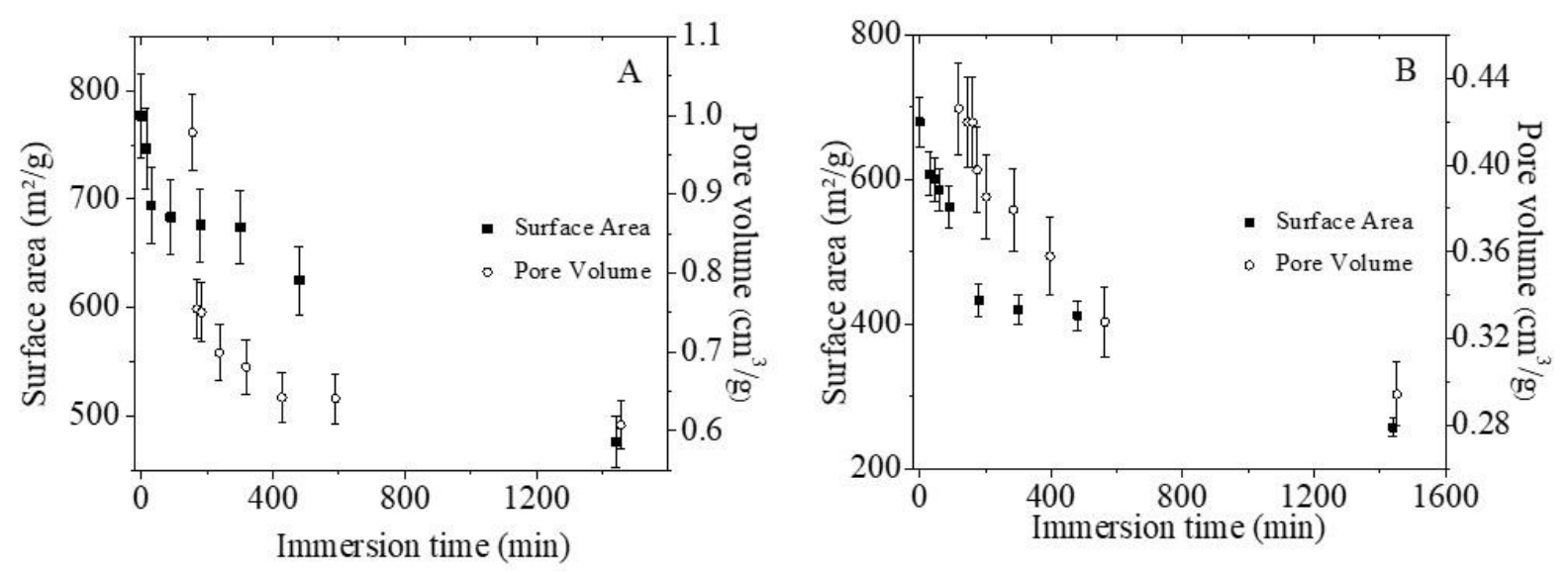

Figure 7: Evolution of the surface area and pore volume as a function of the immersion time for the extracted (A) or extracted and calcined (B) macro-mesoporous material.

The mercury intrusion porosimetry showed that for both the un-calcined and the extracted and calcined material, the macropores are still detected even after 24 hours in boiling water (Fig. 8). Although we can note a slight decrease in the $\mathrm{dV} / \mathrm{dD}$ values, no significant change is noted 
in the shape of the macropores size distribution for both materials. This shows that the macropores are much more stable than the mesopores.
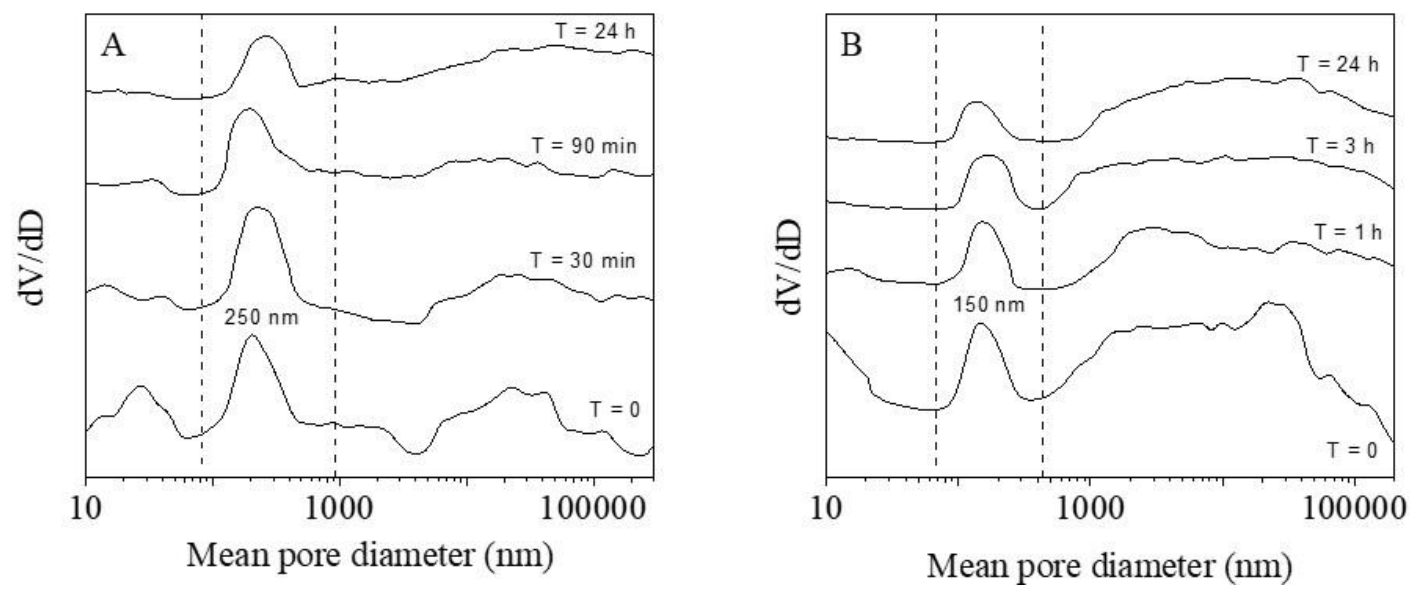

Figure 8: Mercury intrusion porosimetry as a function of the immersion time for the extracted (A) or extracted and calcined (B) macro-mesoporous material.

\subsection{Discussion}

All the samples investigated behave in a similar way when they are plunged into boiling water. The value of the specific surface area decreases and the mesostructure progressively collapses. This phenomenon can be explained by considering the surface features of the materials. Indeed, in aqueous solution TMOS is hydrolyzed and condensed to form polymeric species composed of Si-O-Si units, according to the following equations:

$$
\begin{aligned}
& \equiv \mathrm{Si}-\mathrm{OCH}_{3}+\mathrm{H}_{2} \mathrm{O}=\equiv \mathrm{Si}-\mathrm{OH}+\mathrm{CH}_{3} \mathrm{OH} \text { (hydrolysis) } \\
& \equiv \mathrm{Si}-\mathrm{OH}+\mathrm{OH}-\mathrm{Si} \equiv=\equiv \mathrm{Si}-\mathrm{O}-\mathrm{Si}+\mathrm{H}_{2} \mathrm{O} \text { (condensation) }
\end{aligned}
$$

During the condensation and polymerization of TMOS, silanol groups are formed at the surface and the water adsorbed onto these silanol groups causes the hydrolysis of nearby SiO-Si bonds, resulting in the gradual collapse of the ordered mesoporous structure ${ }^{[34,35]}$. To support this hypothesis, the different porous materials have been investigated by infrared spectroscopy. 

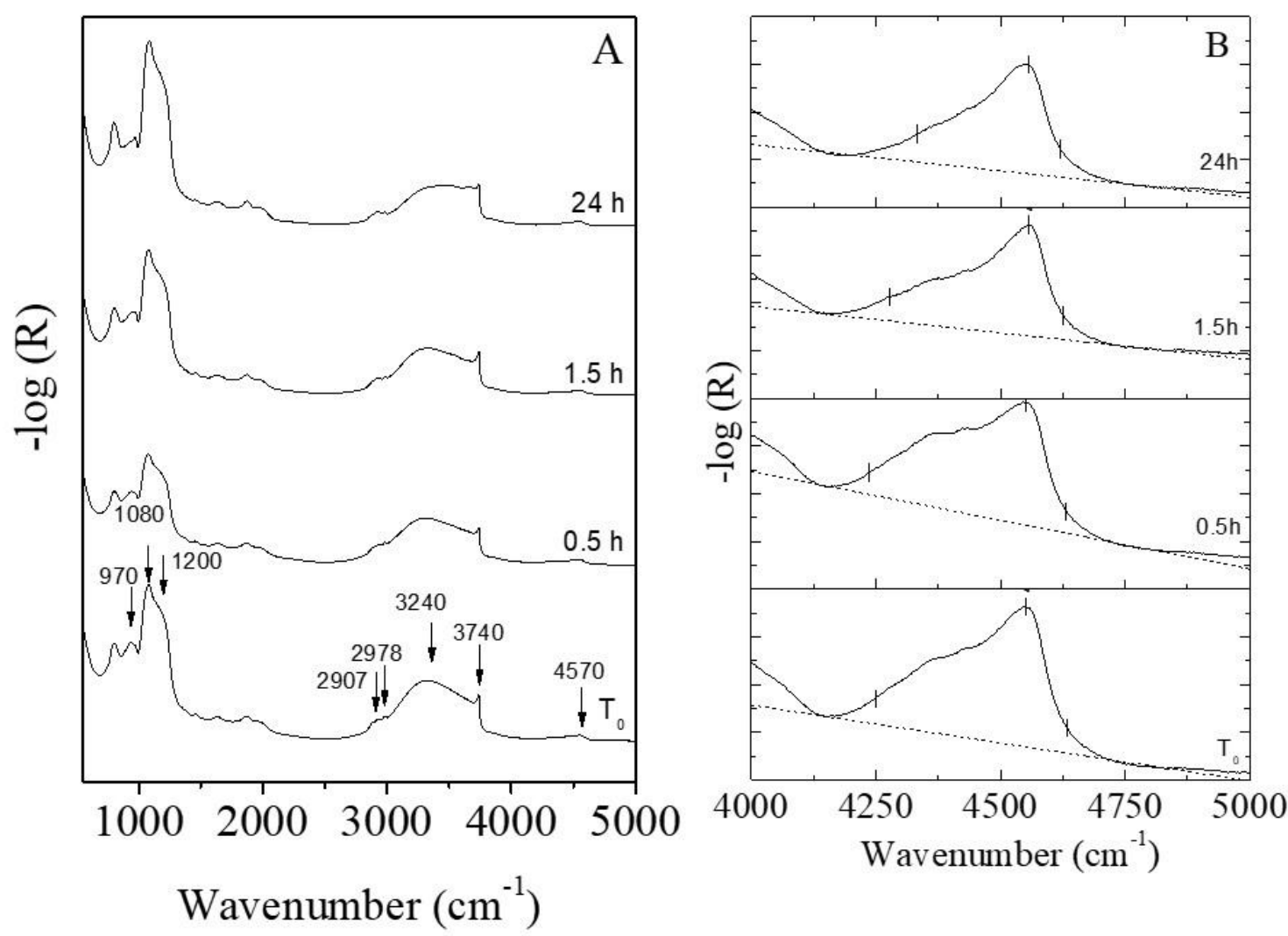

Figure 9: Infrared spectra of the extracted macro-mesoporous silica (A) and variation of the band at $4570 \mathrm{~cm}^{-1}(\mathrm{~B})$ as a function of the immersion time.

It is noteworthy that all the analyzed samples were dehydrated at room temperature under $10^{-5}$ Torr in order to eliminate physisorbed water. In these conditions, all the adsorbed water can be removed ${ }^{[36]}$. As an example, Figure 9A displays the infrared spectra of the extracted macro-mesoporous silica as a function of the immersion time in boiling water. The two other materials present similar spectra. The vibrations of the silica matrix are detected on the infrared spectrum below $1800 \mathrm{~cm}^{-1}$. The broad and intense band with a maximum at $1080 \mathrm{~cm}^{-}$ ${ }^{1}$ as well as the shoulder at $1200 \mathrm{~cm}^{-1}$ are characteristic of the antisymmetric stretching vibrational mode of the $\mathrm{Si}-\mathrm{O}-\mathrm{Si}$ siloxane bridges. The less intense absorption at $970 \mathrm{~cm}^{-1}$ is assigned to the Si-O stretching of silanols. Bands detected at 2978 and $2907 \mathrm{~cm}^{-1}$ are assigned to the stretching vibrations of the $\mathrm{CH}$ groups of the surfactant and hydrocarbons, which was 
not completely removed for the initial material by the ethanol extraction, but are not present in the calcined material. The $\mathrm{H}$-bonded, $\mathrm{OH}-$ groups with various $\mathrm{OH}$...H distances are responsible for the intense absorption below $3700 \mathrm{~cm}^{-1}$ whereas the sharp band at $3740 \mathrm{~cm}^{-1}$ is due to the isolated silanols. The band at $4570 \mathrm{~cm}^{-1}$ in the near infrared spectral is assigned to the combination of stretching $\mathrm{OH}$ and bending $\mathrm{Si}-\mathrm{OH}[(v+\delta) \mathrm{OH}]^{[37,38]}$. It is well known that hydrogen bonding decreases the characteristic wavenumber of the stretching $\mathrm{vOH}$ but also strongly increases the intensity of this fundamental transition. On the contrary, the $\mathrm{OH}$ absorptions in the near spectral range (combination and overtone) are weakly dependent on the H-bond effects ${ }^{[38]}$. Therefore, the area of the silanol combination band between 4100 and $4800 \mathrm{~cm}^{-1}$ can be used to follow the amount of silanols as a function of the immersion time in boiling water.

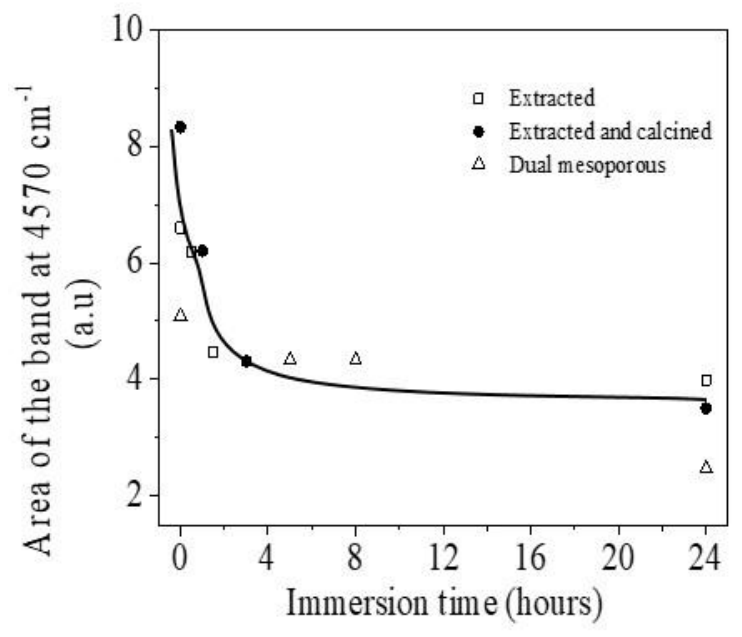

Figure 10 : Evolution of the area of the band at $4570 \mathrm{~cm}^{-1}$ as a function of the immersion time into boiling water.

From Figure 9 it is obvious that the intensity of both the broad absorption around $3240 \mathrm{~cm}^{-1}$ and of the isolated silanols at $3740 \mathrm{~cm}^{-1}$ strongly decreases after the treatment with boiling water. This indicates that the amount of silanol groups has dropped. Indeed, as depicted by Figure 10 for all the considered materials the area of the band at $4570 \mathrm{~cm}^{-1}$ drops at the 
beginning and remains almost constant after 3 hours. ${ }^{29} \mathrm{Si}$ NMR analysis (Fig. 11) also supports the decrease of silanol groups when the various porous materials are plunged in boiling water. ${ }^{29}$ Si MAS+DEC NMR spectra display ${ }^{29} \mathrm{Si}$ MAS+DEC NMR spectra display 3 broad resonances at about $-92,-101.6$ and $-111 \mathrm{ppm}$ corresponding to $\mathrm{Q}^{2}\left((\mathrm{HO})_{2}-\mathrm{Si}-(\mathrm{O}-\right.$ $\left.\mathrm{Si} . ..)_{2}\right), \mathrm{Q}^{3}\left((\mathrm{HO})-\mathrm{Si}-(\mathrm{O}-\mathrm{Si} \ldots)_{3}\right)$ and $\mathrm{Q}^{4}\left(\mathrm{Si}-(\mathrm{O}-\mathrm{Si})_{4}\right)$ units. The presence of $\mathrm{Q}^{2}$ and $\mathrm{Q}^{3}$ reflects the presence of Si-OH groups. From the deconvolution of spectra with DMFIT software ${ }^{[39]}$, the relative amounts of $\mathrm{Q}^{\mathrm{n}}$ units were determined and the numbers of $\mathrm{OH}$ groups $\left(\mathrm{n}_{\mathrm{OH}}\right)$ were calculated (Table 2). The $\mathrm{Q}^{4} /\left(\mathrm{Q}^{2}+\mathrm{Q}^{3}\right)$ ratio highly increases for both extracted macromesoporous silica and dual mesoporous silica materials after $24 \mathrm{~h}$ in boiling water, indicating an increase of the degree of condensation of the silica network. Upon treatment in boiling water, some silanol groups condense to form siloxane bond. As a consequence, a clear decrease of $\mathrm{n}_{\mathrm{OH}}$ is observed for both macro-mesoporous silica and dual-mesoporous silica after boiling $24 \mathrm{~h}$ in water, from $6.8 \times 10^{-3}$ to $4.8 \times 10^{-3}$ and from $6.4 \times 10^{-3}$ to $2.7 \times 10^{-3} \mathrm{~mol} . \mathrm{g}^{-}$ ${ }^{1}$, respectively.

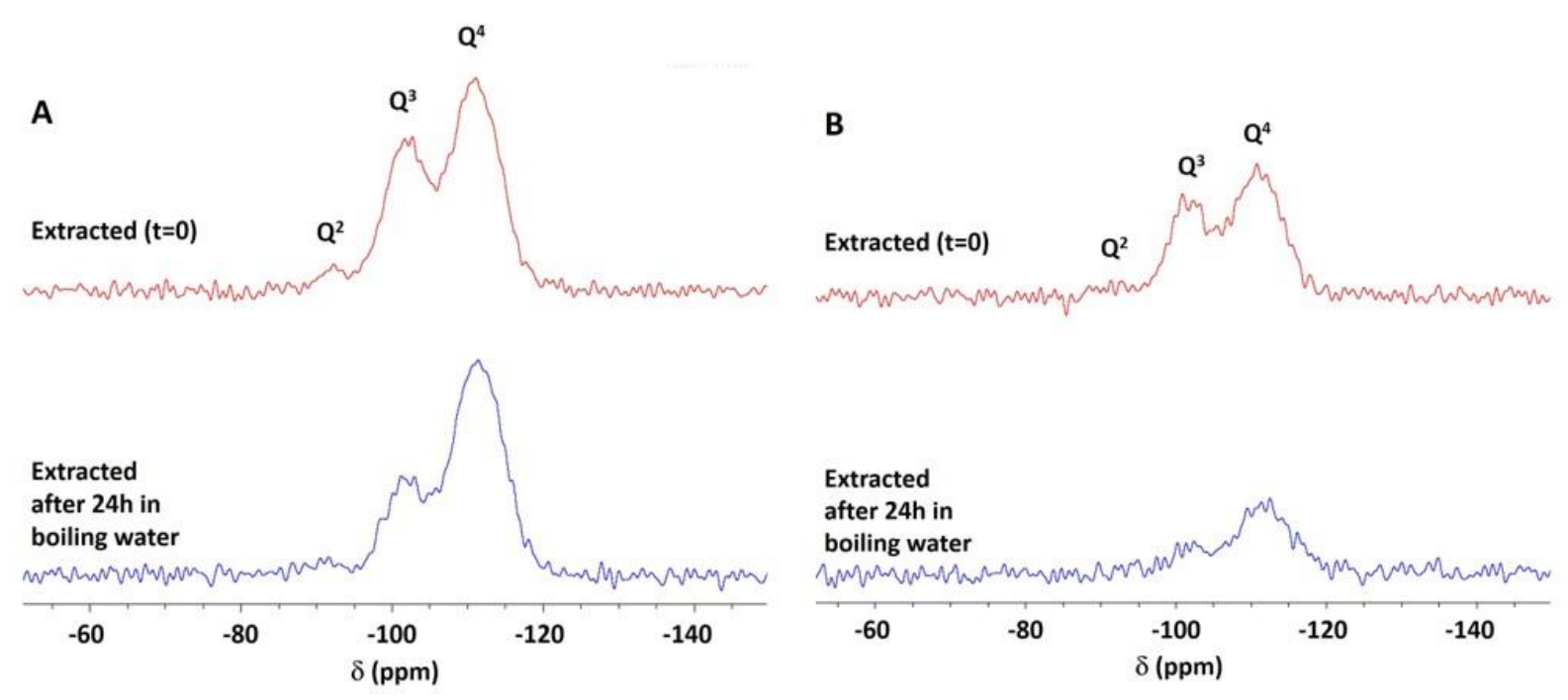

Figure 11: ${ }^{29} \mathrm{Si}$ NMR MAS+DEC spectra of macro-mesoporous silica (A) and of dual mesoporous silica (B) after extraction in $\mathrm{EtOH}$ and after $24 \mathrm{~h}$ in boiling water 
Table 2: relative amounts of siliceous $\mathrm{Q}^{\mathrm{n}}$ units, $\mathrm{Q}^{4} /\left(\mathrm{Q}^{2}+\mathrm{Q}^{3}\right)$ ratio and number of $\mathrm{OH}$ groups determined from ${ }^{29} \mathrm{Si}$ MAS+DEC NMR of macro-mesoporous silica and of dual mesoporous silica after extraction in EtOH and after 24h in boiling water.

\begin{tabular}{cccccc}
\hline samples & $\mathrm{Q}^{2}(\%)$ & $\mathrm{Q}^{3}(\%)$ & $\mathrm{Q}^{4}(\%)$ & $\mathrm{Q}^{4} /\left(\mathrm{Q}^{2}+\mathrm{Q}^{3}\right)$ & $\mathrm{n}_{\mathrm{OH}}\left(\mathrm{mol.g} \mathrm{g}^{-1}\right)$ \\
\hline Macro-mesoporous silica extracted & 4.0 & 35.7 & 60.3 & 1.52 & $6.8 \times 10^{-3}$ \\
Macro-mesoporous silica after 24h in boiling water & 2.9 & 24.6 & 72.5 & 2.64 & $4.8 \times 10^{-3}$ \\
Dual mesoporous silica extracted & 3.0 & 34.9 & 62.1 & 1.64 & $6.4 \times 10^{-3}$ \\
Dual mesoporous silica after 24h in boiling water & 2.2 & 10.7 & 79.1 & 6.13 & $2.7 \times 10^{-3}$ \\
\hline
\end{tabular}

The presence of the silanol groups facilitates the attack of the silica surface by water. The hydrolysis process can break many superficial $\mathrm{Si}-\mathrm{O}-\mathrm{Si}$ linkages to yield more or less branched $(\mathrm{Si}-\mathrm{O}-)_{\mathrm{n}}$ chains. In addition, depolymerisation processes can lead to the formation of orthosilicic acid molecules and small silica oligomers according to the equation:

$\left(\mathrm{SiO}_{2}\right) \mathrm{n}+2 \mathrm{H}_{2} \mathrm{O} \rightarrow\left(\mathrm{SiO}_{2}\right)_{\mathrm{n}-1}+\mathrm{Si}(\mathrm{OH})_{4}$

As a result, the collapse of the mesoporous network occurs ${ }^{[13,24,35]}$. In the case of the dualmesoporous material, because of the thinner walls, the small mesopores network is more subjected to the attack by water and collapses first.

\section{Conclusion}

The calcination of the macro-mesoporous material causes a slight deconstruction of the mesopore network. On the other hand, the calcination of the dual-mesostructured material at several temperatures leads to a complete collapse of the matrix having small mesopores while the matrix having large mesopores is partially affected. This difference in stability between the two matrices of the same material is attributed to the thickness of the pore wall.

The hydrothermal stability of calcined and non-calcined macro-mesoporous materials was compared. The non-calcined material loses the mesostructuration after 30 minutes, whereas 
the calcined material remains stable for 1 hour. The low content of isolated silanols in the calcined material can explain its better hydrothermal stability. Concerning the dual mesoporous material, the evaluation of its hydrothermal stability shows that the matrix having small pores is completely destroyed after 5 hours and the matrix having large pores is more resistant. The difference in behavior of the two matrices is due to the thickness of the walls: the thicker the wall is, the more stable the matrix is.

\section{Experimental section}

The different hierarchical porous silica materials have been prepared according to procedures previously reported ${ }^{[21,22]}$. The poly(ethylene oxide)-poly(propylene oxide)-poly(ethylene oxide) block copolymer Pluronic P123 (EO $)_{20}(\mathrm{PO})_{70}(\mathrm{EO})_{20}$, was purchased from Aldrich. The used fluorinated surfactant, which was provided by DuPont, has an average chemical structure of $\mathrm{C}_{8} \mathrm{~F}_{17} \mathrm{C}_{2} \mathrm{H}_{4}\left(\mathrm{OC}_{2} \mathrm{H}_{4}\right)_{9} \mathrm{OH}$. It is labeled as $\mathrm{R}_{8}^{\mathrm{F}}(\mathrm{EO})_{9}$. The hydrophilic chain moiety exhibits a Gaussian chain length distribution and the hydrophobic part is composed of well-defined mixture of fluorinated tails. Nonionic Remcopal 4 (commercial name) was provided by CECA. It is a technical grade surfactant, which formula mainly consists of a hydrogenated carbon chain with 12 carbons and the average number of oxyethylene is 4 . Its HLB value is 9.7.

Dual-mesoporous material preparation ${ }^{[21]}$ : The dual-mesoporous material was prepared from the Pluronic $(\mathrm{P} 123) / \mathrm{C}_{8} \mathrm{~F}_{17} \mathrm{C}_{2} \mathrm{H}_{4}\left(\mathrm{OC}_{2} \mathrm{H}_{4}\right)_{9} \mathrm{OH}\left[\mathrm{R}_{8}^{\mathrm{F}}(\mathrm{EO})_{9}\right]$ surfactant mixture. First a micellar solution was prepared from $1 \%$ of $\mathrm{P} 123$ and $9 \%$ of $\mathrm{R}_{8}{ }_{8}(\mathrm{EO})_{9}$. The $\mathrm{pH}$ was stabilized at 0.3 using $\mathrm{HCl}$. The surfactant/TMOS ratio was fixed to 0.1. The TMOS is added dropwise to the solution and stirred for 1 hour. Then the solution was transferred to an autoclave which undergoes a hydrothermal treatment at $80^{\circ} \mathrm{C}$ for 24 hours. 
Macro-mesoporous material preparation ${ }^{[22]}$ : The meso-macroporous material were prepared by "Dual Templating", the template for the macropores are nano-emulsions. The nanoemulsions are prepared by the Phase Inversion Temperature (PIT)method. A mixture containing $20 \%$ decane, $6.6 \%$ of Remcopal 4 and water at $\mathrm{pH} 0$ is done, then the nanoemulsions are formed by PIT. As for the mesopores, a micellar solution of 5\% of P123 at pH 0 is prepared. Finally, the nano-emulsions and the micellar solution are mixed with a ratio of 1:1 for 30 seconds. The TMOS is added dropwise for a molar ratio of 0.0025 . The mixture is stirred for 1 hour then transferred to an autoclave which undergoes a hydrothermal treatment at $40^{\circ} \mathrm{C}$ for 24 hours, then at $100^{\circ} \mathrm{C}$ for 48 hours.

Whatever the hierarchical porous material, the final products are recovered after ethanol extraction with a Soxhlet apparatus during 48 hours. The infrared analyzes show that all the surfactant is not completely removed. However, since surfactants vibrations are not observed without treatment under vacuum to remove physisorbed water, we can assume that the quantity of surfactant remaining after extraction is low.

Thermal stability: The first step was accomplished under a nitrogen atmosphere. The samples were heated to $150^{\circ} \mathrm{C}$ at a rate of $1{ }^{\circ} \mathrm{C} / \mathrm{min}$ and remained during one hour at this temperature. Then, the same program was applied to reach $350^{\circ} \mathrm{C}$ and the final desired calcination temperature. When final temperature was reached $\left(350,400,450\right.$ and $\left.550^{\circ} \mathrm{C}\right)$, the flow of oxygen was introduced and the calcination at this step was maintained for 1 hour.

Hydrothermal stability:

Evaluation of the hydrothermal stability: To carry out this study, porous materials, free of surfactants, were refluxed in deionized water at $120^{\circ} \mathrm{C}$ under stirring. After immersion times, varying from 2 minutes to 72 hours, samples were withdrawn from the solution. They were recovered by filtration and dried in air at room temperature. 
Characterization: Small angle X-Ray scattering (SAXS) data were collected on a "SAXSess $\mathrm{mc}^{2 "}$ instrument (Anton Paar), using line-collimation system. This instrument is attached to a ID 3003 laboratory X-Ray generator (General Electric) equipped with a sealed X-Ray tube (PANalytical, $\lambda \mathrm{Cu}, \mathrm{K} \alpha=0.1542 \mathrm{~nm}$ ) operating at $40 \mathrm{kV}$ and $50 \mathrm{~mA}$. Each sample was introduced in a "Special Glass" capillary for liquids and liquid crystals $(\Phi=1.5 \mathrm{~mm}$ and 2.0 $\mathrm{mm}$ for micellar solutions and liquid crystals, respectively), or between two sheets of Kapton ${ }^{\circledR}$ for materials, then placed inside an evacuated sample chamber, and exposed to XRay beam. Scattering of X-Ray beam was registered by a CCD detector (Princeton Instruments, 2084 x 2084 pixels array with $24 \times 24 \mu \mathrm{m}^{2}$ pixel size) at $309 \mathrm{~mm}$ distance from the sample. Using SAXSQuant software (Anton Paar), the 2D image was integrated into onedimensional scattering intensities $\mathrm{I}(\mathrm{q})$ as a function of the magnitude of the scattering vector $\mathrm{q}$ $=(4 \pi / \lambda) \sin (\theta)$, where $2 \theta$ is the total scattering angle. Thanks to a translucent beamstop allowing the measurement of an attenuated primary beam at $q=0$, all measured intensities can therefore be calibrated by normalizing the attenuated primary intensity. Data were then corrected for the background scattering from the cell and for slit-smearing effects by a desmearing procedure from SAXSQuant software, using Lake method. For micellar solutions, after treatment, obtained intensities were scaled into absolute units using water as a reference material.

Nitrogen adsorption and desorption isotherms were determined on a Micromeritics TRISTAR 3000 sorptometer at $-196{ }^{\circ} \mathrm{C}$ over a wide relative pressure range from 0.01 to 0.995 . The pore diameter and the pore size distribution were determined by the BJH (Barret, Joyner, Halenda) method $^{[40]}$ applied to the adsorption branch of the isotherm. Intrusion/extrusion mercury porosimetry were measured with a Micromeritics Autopore IV 9500 porosimeter. 
The infrared spectra were recorded on a Fourier transform infrared spectrometer (Nicolet 8700), equipped with a $\mathrm{KBr}$ beam splitter and a DTGS detector. The spectra in diffuse reflectance (DRIFTS) mode were collected using a Harrick Praying Mantis ${ }^{\mathrm{TM}}$ diffuse reflection accessory and a HVC-DRP reaction chamber. To perform the analysis, the mesoporous powder was first diluted in a $\mathrm{KBr}$ matrix (10 wt.\%). Then the sample was kept inside the evacuated chamber $\left(10^{-5}\right.$ Torr). Reflectances $R_{s}$ of the sample and $R_{r}$ of pure $\mathrm{KBr}$, used as a non-absorbing reference powder, were measured under the same conditions. The mesoporous reflectance is defined as $R=R_{s} / R_{r}$. The spectra are shown in pseudo-absorbance $(-\log R)$ mode. The DRIFT technique was employed instead of the conventional transmission method with pressed wafers to avoid destruction of porous structures under pressure.

${ }^{29}$ Si NMR MAS+DEC (mas angle spinning with proton decoupling) spectra were recorded on Bruker $400 \mathrm{MHz}$ spectrometer at a frequency of $79 \mathrm{MHz}$, with a $\pi / 6$ pulse of $1.77 \mu$ s of and a recycle delay of 80s (about 2200 - 3000 scans per spectrum). Samples were introduced in 4 $\mathrm{mm} \mathrm{ZrO}_{2}$ rotor and spinning rate was $4 \mathrm{kHz}$.

\section{Acknowledgments}

The NMR platforms of IS2M is acknowledged. Severinne Rigolet is warmly thanked for her help in NMR acquisition data. 


\section{References}

[1] A. Corma, Chem. Rev. 1997, 97, 2373-2420.

[2] U. Ciesla, F. Schüth, Microporous. Mesoporous. Mater. 1999,27, 131-149.

[3] M. Vallet-Regi, A. Ramila, R.P. Del Real, J. Pérez-Pariente, Chem. Mater. 2001, 13, $308-311$.

[4] X. Xu, B. Tian,. J. Kong, S. Zhang, B. Liu, D. Zhao, Adv. Mater. 2003, 15, 1932-1936.

[5] Z. Dai, S. Liu, H. Ju, H. Chen, Biosens. Bioelectron. 2004, 19, 861-867.

[6] E. Magner, Chem. Soc. Rev. 2013, 42, 6213-6222.

[7] A. Galarneau, M. Mureseanu, S. Atger, G. Renard, F. Fajula, New J. Chem. 2006, 30, $562-571$.

[8] H. Wang, Y. Jiang, L. Zhou, Y. He, J. Gao, J. Mol. Catal. B Enzym. 2013, 96, 1-5.

[9] J. Jacoby, A. Pasc, C. Carteret, F. Dupire, M.J. Stébé, V. Coupard, J.L. Blin, Process Biochem. 2013, 48, 831-837.

[10] E. F. Vansant, P. Van Der Voort, K. C. Vrancken Characterization and Chemical Modification of the Silica Surface. Vol. 93, Elsevier Science, Amsterdam The Netherlands, 1995.

[11] X.S. Zhao, F. Audsley, C.Q. Lu, J. Phys. Chem. B 1998, 102, 4143-4146.

[12] M.V. Landau, S.P. Varkey, M. Herskowitz, O. Regev, S. Pevzner, T. Sen, Z. Luz, Microporous Mesoporous Mater. 1999, 33, 149-163.

[13] P. Van Der Voort, M.Baltes, E. F. Vansant, Catal. Today 2001, 68, 119-128.

[14] S. Kawi, S.-C. Shen, Mater. Lett. 2000, 42, 108-112.

[15] R. Mokaya, J. Phys. Chem. B 1999, 103, 10204-10208.

[16] T. Linssen, K. Cassiers, P. Cool, E. Vansant, Adv. Colloid Interface Sci. 2003, 103, 121-147.

[17] L.Y. Chen, S.E. Jaenicke, G.K. Chuah, Microporous Mater. 1997, 12 , 323-330. 
[18] K.A. Koyano, T. Tatsumi, Y. Tanaka, S.J. Nakata, J. Phys. Chem. B 1997, 101, 94369440.

[19] R. Mokaya, W. Jones, Chem. Commun. 1998, 0, 1839-1840.

[20] L.Y. Chen, T. Horiuchi, T. Mori, K. Maeda, J. Phys. Chem. B 1999, 103, 1216-1222.

[21] A. May, M.J. Stébé, J. M. Gutiérrez, J.L. Blin, Langmuir 2011, 27, 14000-14004.

[22] P. Riachy, M.J. Stébé, B. Lebeau, A. Pasc, L. Vidal, J.L. Blin Microporous Mesoporous Mater. 2016, 221, 228-237.

[23] A. Léonard, J.L. Blin and B.L. Su, Colloids and Surface A : Pthysicochem. Eng. Aspects 2004, 241, 87-93.

[24] D. Zhao, Q. Huo, J. Feng, B.F. Chmelka, G.D. Stucky, J. Am. Chem. Soc. 1998, 120, 6024-6036.

[25] F. Michaux, C. Carteret, M.J. Stébé, J.L. Blin, Microporous Mesoporous Mater. 2008, $116,308-317$.

[26] Y. Inaki, H. Yoshida, K. Kimura, S. Inagaki, Y. Fukushima, T. Hattori, Phys. Chem. Chem. Phys. 2000, 2, 5293-5297.

[27] J. Schmitt, N. Canilho, M. Imp'ror-Clerc, J.L. Blin, J.S. Pedersen, J. Pérez, B. Lebeau, L. Vidal, M.J. Stébé, ChemPhysChem 2015, 16, 3637-3641.

[28] D. Zhao, J. Feng, Q. Huo, N. Melosh, G. Fredrickson, B. Chmelka, G.D. Stucky, Science 1998, 279, 548-552.

[29] K.S.W. Sing, D.H. Everett, R.A.W Haul, L. Moscou, R.A. Pierotti, J. Rouquerol, T. Siemieniewska, T., IUPAC, Pure and Appl. Chem. 1985, 57, 603-619.

[30] Y.K. Bae, O.H. Han, Microporous Mesoporous Mater. 2007, 106, 304-307.

[31] B. Tian, X. Liu, C. Yu, F. Gao, Q. Luo, S. Xie, B. Tu, D. Zhao, Chem. Commun. 2002, $11,1186-1187$.

[32] M. Kruk, M. Jaroniec, C.H. Ko, R. Ryoo, Chem. Mater. 2000, 12, 1961-1968. 
[33] J. Esquena, C. Rodríguez, C. Solans, H. Kunieda, Microporous Mesoporous Mater. 2006, 92, 212-219.

[34] S. Shen, S. Kawi, J. Phys. Chem. B 1999, 103, 8870-8876.

[35] J.M. Kim, R. Ryoo, Bull. Korean Chem. Soc. 1996, 17, 66-68.

[36] J.L. Blin, C. Carteret, J. Phys. Chem. C 2007, 111, 14380-14388.

[37] A. Burneau, C. Carteret, Phys. Chem. Chem. Phys. 2000, 2, 3217-3226.

[38] C. Carteret, J. Phys. Chem. C 2009, 113, 1330-13308.

[39] D. Massiot, F. Fayon, M. Capron, I. King, S. Le Calvé, B. Alonso, J.-L. Durand, B. Bujoli, Z. Gan, G. Hoatson, Magn. Reson. Chem. 2002, 40, 70-76.

[40] E.P. Barret, L.G. Joyner, P.P. Halenda, J. Am. Chem. Soc. 1951, 73, 373-380. 


\section{Graphical abstract}

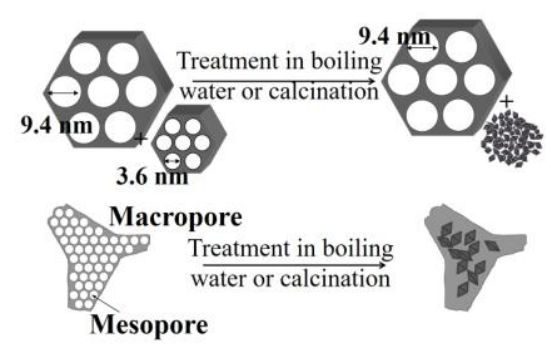

\section{Table of content}

The mesopores wall thickness and the silanol groups are the key parameters for the thermal and hydrothermal stability of hierarchical porous silica materials. The collapse of the silica matrix is due to the collapse of the small mesopore network, the thicker the pore wall is, the more stable the material is.

\section{Key topic}

Hierarchical porosity 